Research Article

\title{
Intuitionistic Fuzzy Factorial Analysis Model for Supplier Selection of Urban Rail Transit Companies within a Random Environment
}

\author{
Hui Sun $\mathbb{D}^{1},{ }^{1}$ Hanlin Li $\mathbb{D}^{1},{ }^{1}$ Yuning Wang $\mathbb{D}^{2},{ }^{2}$ and Yufei Yang $\mathbb{D}^{3}$ \\ ${ }^{1}$ School of Management and Economics, Tianjin University, Tianjin, China \\ ${ }^{2}$ School of Geographic and Environmental Sciences, Tianjin Normal University, Tianjin, China \\ ${ }^{3}$ School of Public Finance \& Economics, Shanxi University of Finance and Economics, Taiyuan, Shanxi, China
}

Correspondence should be addressed to Yuning Wang; wangyn8158@126.com

Received 9 October 2020; Revised 14 March 2021; Accepted 31 March 2021; Published 15 April 2021

Academic Editor: Gordon Huang

Copyright $(92021$ Hui Sun et al. This is an open access article distributed under the Creative Commons Attribution License, which permits unrestricted use, distribution, and reproduction in any medium, provided the original work is properly cited.

Facing serious environmental and traffic problems, urban rail transit companies, with the features of large capacity and high efficiency, have become an important choice for many large cities that are prioritizing public transportation and encouraging green travel options. As the construction speed of rail transit projects accelerates, the demand for materials and devices required for construction and operation is also increasing for urban rail transit companies. Therefore, the scientific selection of suppliers to meet construction and operation demands has become a problem that must be addressed. This paper presents an intuitionistic fuzzy factorial analysis model in a random environment, where correlative phenomena among each of the indicators and a random decision-making environment are considered. The evaluation indicator system of rail suppliers is established by considering the influencing factors. The extracted common factors indicate the nature of the studied object in a most direct way. The suppliers are evaluated from the perspective of the number of intuitionistic fuzzy factors and are ranked by their scores. Finally, the Tianjin urban rail transit company is used as a case study to illustrate the validity and feasibility of the method. The results can help urban rail transit companies improve their existing supplier selection method.

\section{Introduction}

In recent years, China has accelerated the urbanization process, which has led to urban population growth. This has raised people's living standards on the one hand, but on the other hand, the expansion of cities will increase bus service usage, the average travel distance, and commuting time. As they are facing increasingly serious environmental and traffic problems, urban rail transit companies, with the features of a large capacity, high efficiency, low-carbon emissions, and a lack of restrictions in terms of aboveground land rights, have become an important choice for many large cities for prioritizing public transportation and encouraging green travel. In the past 10 years, 29 cities in China have opened urban rail transit systems, and the total mileage has quadrupled. Urban rail transit construction in China has already reached a climax. As of June 2020, 37 cities in China have been successfully served by underground railways, and the total length of the underground railways is over 4600 kilometres. Most of them are still extending their networks. As the demand for materials and devices required for construction and operation increases, purchasing management will face new and greater challenges. For example, urban rail transit projects are susceptible to unforeseen factors such as aboveground objects, uncontrollable weather, and changeable policies that affect the process of construction. These factors will cause a large deviation between purchase planning and the actual situation, increasing the difficulty of analysing the purchase demand and creating and implementing a plan. Therefore, the traditional purchasing pattern and purchase conception of urban rail transit are far from sufficient to satisfy increasing needs. Moreover, 
compared with other urban transit projects, urban rail transit projects are more complex, involving large construction scales, long construction periods, more stringent technology requirements, and susceptibility to environmental factors. Therefore, such rail projects have higher requirements for product quality and reliability.

Compared with other supplier selection issues, subway equipment suppliers have certain characteristics. (1) Large quantities: there are many types of subway equipment, involving vehicle systems, signal systems, communication systems, and power supply systems, resulting in a much higher number of suppliers than ordinary project suppliers. (2) Multiple components: although the localization rate of subway equipment has increased significantly, some core system equipment still needs to be purchased from foreign companies. Therefore, the composition of subway equipment suppliers is higher than the ordinary project suppliers. (3) High cost: the subway system is a high-tech industry. The subway equipment production system is difficult to adapt to the equipment production of other projects, resulting in the overall cost of subway equipment suppliers higher than ordinary project suppliers. (4) High complexity: the subway project has long lines, complex underground operating environment, and strong cross-specialization of subway equipment. The combination of multiple professional equipment and multiple systems makes subway projects far more complex than ordinary projects.

The appropriate supplier needs to deliver high-quality and high-tech equipment within the given time. The appropriate supplier is a necessary condition for the success of a subway project. The difficulties in the selection of subway suppliers are summarized as follows. (1) High complexity of evaluation: there are a large number of evaluation indicators for subway suppliers, and there are some similarities and contradictions among the indicators. Due to the large number of types of subway project equipment and wide cross-disciplinary scope, the expert group who evaluates subway suppliers is affected by the knowledge level, historical experience and personal preference, and other influences. It is impossible for the expert group to make a completely accurate evaluation of suppliers. (2) Uncertain environment: before the equipment procurement is completely completed, the external environment of the subway and the supplier is constantly changing. The subway project is vulnerable to uncontrollable weather factors, market economy, and policy changes during the construction process. On the one hand, the dynamic changes of the external environment will affect the performance of suppliers and equipment and further affect the evaluation of indicators and supplier selection. On the other hand, it will also lead to a large difference between the original plan and the actual situation, which will increase the project of subway companies.

From the above analysis, we can see that the process of supplier selection is complicated and uncertain. With the rapid development of the subway system, the difficulty of supplier selection is increasing, and the traditional supplier selection method of the subway company is no longer suitable for the new environment. Therefore, how to reduce the impact of these uncertainties and complexity for the selection of subway equipment suppliers, use suitable tools to describe the evaluation information, and construct a model suitable for subway equipment suppliers is very valuable for subway companies.

To cope with these problems, this paper builds a scientific evaluation indicator system for urban rail transit projects and introduces an intuitionistic fuzzy factorial analysis model within a random environment. This model uses intuitionistic fuzzy numbers to handle uncertain information, eliminates overlapping information, and considers the random environment, which affects the performance of the product. The innovation of this paper is as follows: (1) it selects the appropriate forms of data to handle the problem of the cognition levels of decisionmakers. (2) In view of the complexity and variability of the decision-making environment, we introduce the environmental factors. The evaluation information of the decisionmaker is processed through the calculus function which can convert the fixed intuitionistic fuzzy number into the dynamic intuitionistic fuzzy number. (3) We change the value of environmental variables and get the selection results in different decision-making environments, because the evaluation results are dynamic and time-efficient, which are more in line with the actual situation of supplier selection.

The rest of this paper is organized as follows. In Section 2 , we summarize the related literature on supplier selection. In Section 3, we introduce the intuitionistic fuzzy factorial analysis model within a random environment. In Section 4, we provide a real-life case study. The final conclusions are presented in Section 5. The diagram flow of the paper is shown Figure 1.

\section{Literature Review}

2.1. Methods for Supplier Selection. The development of the societal economy enhances the complexity, uncertainty, and strategy of supplier selection. The simple method of competitive bidding is no longer applicable. Therefore, urban rail transit needs new methods to address the complexity of supplier selection. Scholars have conducted a wide range of research on this topic.

Gabriella et al. proposed a generalized net model that could address multiperson, multicriteria decision-making problems [1]. Liao and Rittscher indicated that supplier selection is a typical multicriteria decision problem. They also considered demand quantity and timing uncertainties comprehensively, which extends the measurement of supplier flexibility [2]. Ho et al. reviewed the literature on multicriteria decision-making approaches for supplier selection in international journals from 2000 to 2008 . The result indicates that the multicriteria decision-making methods are better than the traditional cost-based methods [3]. Govindan et al. used the Simos procedure and Preference Ranking Organization Method for Enrichment Evaluation (PROMETHEE) method to evaluate suppliers. The advantage of this combination method is to reduce the gap between individual evaluation results and group evaluation results [4]. Banaeian et al. compared the application of popular multicriteria supplier 


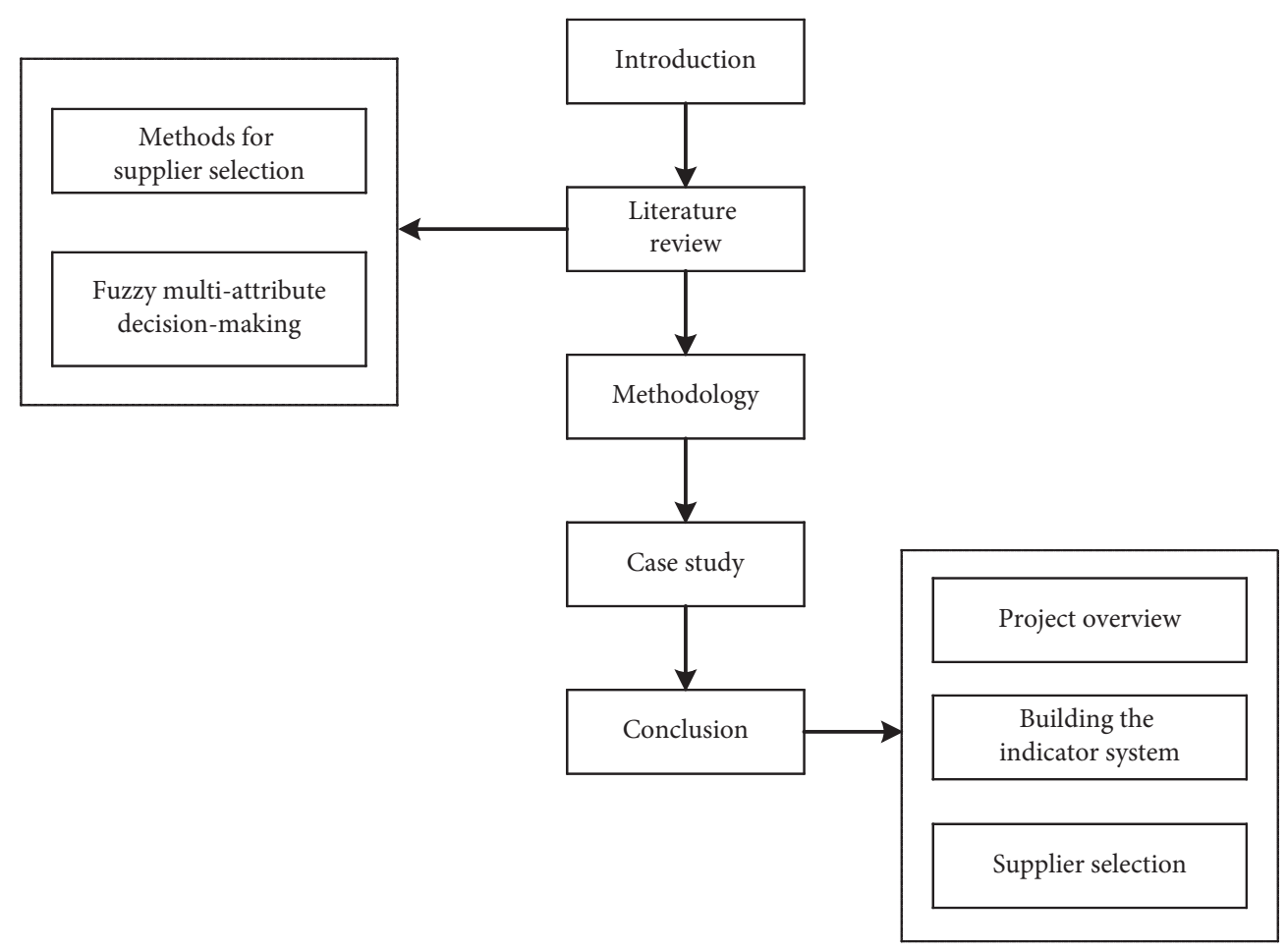

FIgURE 1: The diagram flow of the paper.

selection methods. The result shows that the Technique for Order Preference by Similarity to an Ideal Solution (TOPSIS), VIšekriterijumskoKOmpromisnoRangiranje (VIKOR), and Grey Relational Analysis (GRA) methods produce identical supplier rankings. However, fuzzy GRA requires less computational complexity [5]. Girubha et al. proposed two approaches involving hybrid multicriteria decision-making methods (ISM-ANP-ELECTRE II and ISM-ANP-VIKOR) [6]. Ghoushchi et al. combined target planning and Data envelopment analysis (DEA) model to solve the problem of multiobjective supplier selection. Luan et al. used a hybrid algorithm of genetic algorithm and ant colony algorithm to solve the linear programming model of the supplier selection problem [7]. Wu et al. proposed a novel decision framework within a mixed information environment to address some deficiencies, such as information loss, weight deviation, and the lack of psychological characteristic analysis in supplier selection. The result demonstrates that psychological characteristics such as reference dependence and loss aversion greatly affect the ranking [8].

Reviewing the literature, it can be found that scholars have used different methods to study the problem of supplier selection problem. In the early research literature, scholars are accustomed to using a single decision-making method, such as analytic hierarchy process (AHP), DEA, Linear Programming (LP), and Artificial Intelligence (AI) methods. With the in-depth studying of the problem, scholars have added different theories to the original single method and combined two or more methods into a new method, which overcomes the defects of the original single method. Although the new evaluation method tends to integrate multiple methods, it still has certain shortcomings and cannot well support the following points: (1) reflect evaluation information: the professional knowledge and practical experience of each decision-maker are different. They are limited by subjective and objective factors. They do not have complete knowledge and cannot accurately recognize alternatives. Therefore, the evaluation information is incomplete and the existing methods cannot describe the evaluation information very well. (2) Measure supplier performance under a dynamic environment: the performance of the alternatives is affected by the decision-making environment. Decision-making environment is dynamically changing. The evaluation information given by the decisionmaker may not be consistent with the performance of the alternatives after a period of time. Therefore, we introduce fuzzy set theory in this paper to allow decision-makers to evaluate suppliers more robustly.

2.2. Fuzzy Multiattribute Decision-Making. Zadeh first introduced the fuzzy set, which better describes vague information and considers the membership degree [9]. However, in reality, the complexity of problems, the use of incomplete and fuzzy information, and the uncertain decision environment all make decision-making judgements more difficult. To overcome this limitation, Atanassov used the conceptual definition of the intuitionistic fuzzy set, which is capable of providing a comprehensive description for decision information. This set considers the membership degree, nonmembership degree, and the degree of hesitation [10]. Yager proposed the concept of fuzzy multisets or fuzzy bags, which is a collection. The set contains repeated elements from all with degrees of membership. The 
development of fuzzy sets has promoted the expansion of related academic research [11]. Scholars conducted research from three perspectives: operators, score functions, and decision-making methods.

The first is the research on operators: $\mathrm{Xu}$ and Yager defined the dynamic intuitionistic fuzzy weighted average (IFWA) operator. They also proposed a dynamic intuitionistic fuzzy multiattribute decision-making method. Finally, they extended the method to uncertain dynamic intuitionistic fuzzy environments [12]. Xu and Yager proposed the intuitionistic fuzzy Bonferroni average operator [13]. Xia et al. combined Bonferroni mean and geometric mean, proposing the Bonferroni geometric mean operator [14]. Qin and Liu extended the Maclaurin symmetric mean (MSM) operator to the intuitionistic fuzzy environment, which can better reflect the correlation between attributes [15]. Liu extended the Hamacher average operator to the interval intuitionistic fuzzy environment [16]. Verma and Sharma extended the geometric Heronian mean to the hesitant fuzzy environment, proposing some new geometric mean operators [17]. Based on the q-order neighbor pair fuzzy set, Krishankumar et al. proposed a new operator to calculate the weight of attributes, extending the VIKOR method to the q-order neighbor pair fuzzy environment $[18]$. Papers $[19,20]$ proposed some new operators to determine attribute weights.

The second is the research on score function: based on the intuitionistic fuzzy point operator and evaluation function, Liu and Wang proposed some new score functions and applied them to multiattribute decision-making methods [21]. Wang and Yan proposed a new score function for multiattribute decision sorting based on the study of set pair analysis theory [22]. According to the characteristics of interval intuitionistic fuzzy sets, Tian constructed a new comprehensive weighted mentality function for ranking evaluation results [23]. Zeng et al. proposed a new score function to improve the VIKOR method [24].

The third is the research on decision-making methods: Boran et al. extended the TOPSIS method to the intuitionistic fuzzy environment [25]. Li proposed an improved GRA model based on fuzzy Decision Making Trial And Evaluation Laboratory- (DEMATEL-) Analytical Network Process (ANP), which solved the inconsistency between quantitative results and qualitative analysis results to a certain extent [26]. Chen et al. proposed an intuitionistic fuzzy factorial analysis model that considers the correlative phenomenon among attributes [27]. Jain and Singh proposed a two-stage decision-making model based on the Fuzzy Interference System (FIS). It used the Kano fuzzy concept clustering index on the first stage and ranked suppliers by the FIS system [28]. Chen et al. proposed a hybrid rough-fuzzy DEMATEL-TOPSIS method for sustainable supplier selection. This method uses the advantages of fuzzy sets and rough sets in dealing with internal and external uncertainties [29]. Ali et al. proposed a rough-fuzzy multicriteria decision-making model. This model integrates Fuzzy PIvot Pairwise RElative Criteria Importance Assessment and Interval rough Simple Additive Weighting methods [30]. Xiao et al. proposed a new intuitionistic fuzzy multiattribute decision-making method. Firstly, the attribute weight is determined by the intercorrelation between attributes. Secondly, the Taxonomy method is extended to the intuitionistic fuzzy environment. Finally, get the supplier's score [31]. Zavadskas et al. applied the fuzzy AHP to the selection of suppliers [19]. Papers [32, 33] introduced the distance formula into the supplier selection model. Mishra et al. proposed a multiattribute decision-making method based on distance and intuitionistic fuzzy sets [34].

Scholars have performed much research on multiattribute decision-making methods for operators, score functions, and evaluation methods. The supplier selection problem has the following characteristics: (1) there are lots of evaluation indicators. There is a certain degree of overlap and contradiction between the indicators. (2) The evaluation of qualitative evaluation indicators is easily affected by the professional knowledge and historical experience of decision-makers. (3) The decision-making environment is complex and changeable. The performance of suppliers and product is affected by the rapidly changing economic environment and policy environment, so decision-makers cannot make accurate evaluations. Based on the above problems, we know that the supplier selection process is filled with ambiguity and uncertainty. Therefore, this paper introduces an intuitionistic fuzzy factor analysis model to deal with the above problems. In this model, (1) intuitionistic fuzzy sets handle the uncertainty and ambiguity of the evaluation information. (2) Factor analysis method eliminates the overlap between related indicators. (3) Environmental factors deal with the evaluation information of decision-makers through calculus functions, converting fixed intuitionistic fuzzy numbers into dynamic functions of environmental variables. Finally, we determine the selection results in different decision-making environments by changing the values of environmental variables. Therefore, the evaluation results are dynamic, time-efficient, and more in line with the actual situation of supplier selection.

\section{Methodology}

In this paper, the multicriteria decision-making problem of suppliers of subway projects can be described as follows: there are $n$ suppliers $A=\left\{A_{1}, A_{2}, \ldots, A_{n}\right\}(i=1,2, \ldots, n)$ and $p$ attributes $C=\left\{C_{1}, C_{2}, \ldots, C_{p}\right\}(j=1,2, \ldots, p)$. The evaluation value of supplier $A_{i}$ about attributes $C_{j}$ is $\alpha_{i j}$, where $\alpha_{i j}$ is an intuitionistic fuzzy number. Let $\xi_{1}, \xi_{2}, \ldots, \xi_{p}$ be $p$ random intuitionistic fuzzy vectors, $\xi_{j}=\left\{\alpha_{1 j}, \alpha_{2 j}, \ldots\right.$, $\left.\alpha_{n j}\right\}^{T}$.

\subsection{Basic Concepts}

Definition 1. Let $X$ be a nonempty set. An intuitionistic fuzzy set is described as follows:

$$
A=\left\{x, u_{A}(x), v_{A}(x) \mid x \in X\right\},
$$

where $\quad x \in X, \quad u_{A}(x) \in[0,1], \quad v_{A}(x) \in[0,1], \quad$ and $0 \leq u_{A}(x)+v_{A}(x) \leq 1$. The numbers $u_{A}(x)$ and $v_{A}(x)$ 
represent the membership degree and nonmembership degree of the element $x$ for $A$, respectively.

Definition 2. Let $\alpha_{1}=\left(u_{1}, v_{1}\right), \alpha_{2}=\left(u_{2}, v_{2}\right)$ represent two intuitionistic fuzzy numbers, so four operational rules are described as follows:

(1) $\alpha_{1} \oplus \alpha_{2}=\left(u_{1}+u_{2}-u_{1} u_{2}, v_{1} v_{2}\right)$

(2) $\alpha_{1} \otimes \alpha_{2}=\left(u_{1} u_{2}, v_{1}+v_{2}-v_{1} v_{2}\right)$

(3) $\lambda \alpha_{1}=\left(1-\left(1-u_{1}\right)^{\lambda}, v_{1}^{\lambda}\right), \lambda>0$

(4) $\alpha_{1}^{\lambda}=\left(u_{1}^{\lambda}, 1-\left(1-v_{1}\right)^{\lambda}\right), \lambda>0$

Definition 3. Let $\alpha=(u, v)$ be an intuitionistic fuzzy number. The corresponding score function and accuracy function can be denoted by $S(\alpha)=u-v, T(\alpha)=u+v$. Two intuitionistic fuzzy numbers have been given: $\alpha_{1}=\left(u_{1}, v_{1}\right)$, $\alpha_{2}=\left(u_{2}, v_{2}\right)$.

(1) If $S\left(\alpha_{1}\right)<S\left(\alpha_{2}\right)$, then $\alpha_{1}<\alpha_{2}$

(2) If $S\left(\alpha_{1}\right)=S\left(\alpha_{2}\right), T\left(\alpha_{1}\right)<T\left(\alpha_{2}\right)$, then $\alpha_{1}<, \alpha_{2}$

(3) If $S\left(\alpha_{1}\right)=S\left(\alpha_{2}\right), T\left(\alpha_{1}\right)=T\left(\alpha_{2}\right)$, then $\alpha_{1}=, \alpha_{2}$

Definition 4. Let $\alpha_{i}=\left(u_{i}, v_{i}\right),(i=1,2, \ldots, n)$ represent $n$ intuitionistic fuzzy numbers. The linear combination of $\alpha_{i}$ is described as follows:

$$
i=\sum_{i=1}^{n} \oplus \lambda^{i} \alpha^{i}=(u, v),
$$

where $\quad u=1-(1-u n)^{\lambda n}+\sum_{r=2}^{n}\left[\prod_{i=r}^{n}(1-u i)^{\lambda i}[1-(1-\right.$ $\left.\left.u r-1)^{\lambda r-1}\right]\right]$ and $v=\prod_{i=1}^{n} v i^{\lambda i}$.

Definition 5. Let $\alpha_{i}=\left(u_{i}, v_{i}\right),(i=1,2, \ldots, n)$ represent $n$ intuitionistic fuzzy numbers. The IFWA operator of $\alpha_{i}$ is described as follows:

$$
\begin{aligned}
\operatorname{IFWA}_{w}\left(\alpha_{1}, \alpha_{2}, \ldots, \alpha_{n}\right) & =\omega_{1} \alpha_{1} \oplus \omega_{2} \alpha_{2} \oplus \cdots \oplus \omega_{n} \alpha_{n} \\
& =\left(1-\prod_{i=1}^{n}\left(1-u_{i}\right)^{\omega_{i}}, \prod_{i=1}^{n} v_{i}^{\omega_{i}}\right),
\end{aligned}
$$

where $\omega=\left(\omega_{1}, \omega_{2}, \ldots, \omega_{n}\right)^{T}$ is the weight vector of $\alpha_{1}, \alpha_{2}, \ldots, \alpha_{n}$ and $\omega_{i} \in[0,1], \sum_{i=1}^{n} \omega_{i}=1$.

Definition 6. The mean of $\xi_{j}$ is described as follows:

$$
E\left(\xi_{j}\right)=\frac{1}{n} \sum_{i=1}^{n} \oplus \alpha_{i}=(u, v),
$$

where $\quad u=1-\left(1-u_{n}\right)^{(1 / n)}+\sum_{r=2}^{n}\left[\prod_{i=r}^{n}\left(1-u_{i}\right)^{(1 / n)}[1-\right.$ $\left.\left.\left(1-u_{r-1}\right)^{(1 / n)}\right]\right]$ and $v=\prod_{i=1}^{n} v_{i}^{(1 / n)}$.

Definition 7. The variance of $\xi j$ is described as follows:

$$
D\left(\xi_{j}\right)=\frac{1}{n-1} \sum_{i=1}^{n}\left(\operatorname{diff}\left(\alpha_{i}, E\left(\xi_{j}\right)\right)\right)^{2} .
$$

Definition 8. Let $\xi=\left\{\alpha_{1}, \alpha_{2}, \ldots, \alpha_{n}\right\}$ and $\eta=\left\{\beta_{1}, \beta_{2}, \ldots, \beta_{n}\right\}$ be two random intuitionistic fuzzy variables. The covariance of $\xi$ and $\eta$ is described as follows:

$$
\operatorname{cov}(\xi, \eta)=\frac{1}{n-1} \sum_{i=1}^{n}\left(\operatorname{diff}\left(\alpha_{i}, E(\xi)\right)\left(\operatorname{diff}\left(\beta_{i}, E(\eta)\right)\right) .\right.
$$

Definition 9. Let $\xi=\left\{\alpha_{1}, \alpha_{2}, \ldots, \alpha_{n}\right\}$ and $\eta=\left\{\beta_{1}, \beta_{2}, \ldots, \beta_{n}\right\}$ be two random intuitionistic fuzzy variables. The correlation coefficient of $\xi$ and $\eta$ is described as follows:

$$
\rho(\xi, \eta)=\frac{\operatorname{cov}(\xi, \eta)}{\sqrt{D(\xi)} \sqrt{D(\eta)}} .
$$

Definition 10. The value of $\alpha_{i}=\left(u_{i}, v_{i}\right)$ is easily affected by the random vector $Y=\left\{Y_{1}, Y_{2}, \ldots, Y_{t}\right\}$ in the random environment. $u_{i}$ and $v_{i}$ are no longer certain values but obey the specific distributions $u_{i}(y)$ and $v_{i}(y)$, respectively, where $y$ is the value of $Y$. For example, $\alpha=(u, v)$ is used to describe commodity prices, and the value of $\alpha$ is affected by three random factors: the demand $y_{1}$, the supply $y_{2}$, and the prices of substitutes $y_{3}$. With high demand, low supply, and high prices of substitutes, $\alpha=(0.2,0.7)$. With low demand, high supply, and low prices of substitutes, $\alpha=(0.8,0.1)$.

Definition 11. Let $\alpha_{1}=\left(u_{1}\left(y_{1}\right), v_{1}\left(y_{1}\right)\right)$ and $\alpha_{2}=\left(u_{2}\right.$ $\left.\left(y_{2}\right), v_{2}\left(y_{2}\right)\right)$ represent two intuitionistic fuzzy numbers. The difference between $\alpha_{1}$ and $\alpha_{2}$ is described as follows:

$$
\operatorname{diff}\left(\alpha_{1}, \alpha_{2}\right)=\operatorname{diff}\left(u_{1}\left(y_{1}\right), u_{2}\left(y_{2}\right)\right)-\operatorname{diff}\left(v_{1}\left(y_{1}\right), v_{2}\left(y_{2}\right)\right),
$$

where $\quad \operatorname{diff}\left(u_{1}\left(y_{1}\right), u_{2}\left(y_{2}\right)\right)=\int y_{1} u_{1}^{\prime}\left(y_{1}\right) \mathrm{d} y_{1}-\iint y_{1} y_{2} u_{1}^{\prime}$ $\left(y_{1}\right) u_{2}^{\prime}\left(y_{2}\right) \mathrm{d} y_{1} \mathrm{~d} y_{2}$,

$$
\begin{aligned}
\operatorname{diff}\left(v_{1}\left(y_{1}\right), v_{2}\left(y_{2}\right)\right)= & \int y_{1} v_{1}^{\prime}\left(y_{1}\right) \mathrm{d} y_{1} \\
& -\iint y_{1} y_{2} v_{1}^{\prime}\left(y_{1}\right) v_{2}^{\prime}\left(y_{2}\right) \mathrm{d} y_{1} \mathrm{~d} y_{2} .
\end{aligned}
$$

3.2. Description of the Model. British psychologist Charles Edward Spearman first proposed the factor analysis model for correlation of student grades to verify whether there are potential common factors that affect student performance. This model can decrease the number of factors and then use the common factor to scientifically evaluate the analysed objects. The model which we introduce inherits the advantages of the original model which could deal with the incomplete evaluation information and overlapping effects between indicators. It also has the following advantages: (1) considering the weight of original indicators and experts to improve the rationality of the selection results and (2) considering the impact of environmental factors on the performance of suppliers and products. Fixed evaluation information is transformed into dynamic evaluation information to improve the timeliness of the selection results. The decision model mainly includes eight steps. 
Step 1. Obtain the intuitionistic fuzzy decision matrix $M$ :

$$
M=\left[\begin{array}{ccc}
\alpha_{11} & \ldots & \alpha_{1 p} \\
\vdots & \ddots & \vdots \\
\alpha_{n 1} & \cdots & \alpha_{n p}
\end{array}\right]
$$

Step 2. Find the environmental factors $Y=\left\{Y_{1}, Y_{2}, \ldots, Y_{t}\right\}$,define the distribution functions of the random environmental factors $\alpha_{i j}(y)$, and produce the intuitionistic fuzzy decision matrix within the random environment $M^{*}$ :

$$
M^{*}=\left[\begin{array}{ccc}
\alpha_{11}(y) & \ldots & \alpha_{1 p}(y) \\
\vdots & \ddots & \vdots \\
\alpha_{n 1}(y) & \cdots & \alpha_{n n}(y)
\end{array}\right] .
$$

Step 3. Based on the intuitionistic fuzzy decision matrix within the random environment $M^{*}$ and Definition 9, calculate the correlation matrix of the attributes $R$.

$$
R=\left[\begin{array}{ccc}
r_{11} & \cdots & r_{1 p} \\
\vdots & \ddots & \vdots \\
r_{n 1} & \cdots & r_{n p}
\end{array}\right],
$$

where $r_{i j}=\left(\operatorname{cov}\left(\widetilde{\xi}_{i}, \widetilde{\xi}_{j}\right) / \sqrt{D\left(\widetilde{\xi}_{i}\right)} \sqrt{D\left(\widetilde{\xi}_{j}\right)}\right)$.

Step 4. Based on the correlation matrix $R$, calculate the factor loading matrix $\wedge$ and common factors $F_{o}=\left\{F_{1}, F_{2}, \ldots, F_{m}\right\}$.

(1) Get the eigenvalue $\delta o$ and the corresponding eigenvector $\left(r_{1 o}, r_{20}, \ldots, r_{p o}\right)^{T}$ of the correlation matrix $R$.

(2) Let $\alpha_{k o}=\sqrt{\delta_{o}} r_{j o}$; then the factor loading matrix $\wedge$ can be expressed as

$$
\wedge=\left[\begin{array}{ccc}
\alpha_{11} & \ldots & \alpha_{1 m} \\
\vdots & \ddots & \vdots \\
\alpha_{p 1} & \cdots & \alpha_{p m}
\end{array}\right] .
$$

(3) Denote $\xi j$ by the common component $Z_{o}(o=1,2, \ldots, m)$ and the special factor $\theta j$ :

$$
\xi_{j}=\sum_{o=1}^{m} \oplus\left(r_{o j} Z_{o}+\theta_{j}\right) .
$$

(4) Let $F_{o}=\left(Z_{o} / \sqrt{\delta_{o}}\right)$ and $b_{i j}$ represent the correlation coefficient between $\xi_{j}$ and $F_{o}$. Then the variance contribution of $F_{o}$ is calculated by $v_{o}^{2}$, and the weight vector is described as $\omega_{F o}$.

$$
\begin{gathered}
v_{o}^{2}=\sum_{i=1}^{p} b_{j o}^{2}, \\
\omega_{F o}=\frac{v_{o}^{2}}{\sum_{o=1}^{m} v_{o}^{2}} .
\end{gathered}
$$

(5) According to the selection standard $\left(\delta_{o}>1\right.$ and $\left.v_{o}^{2}>90 \%\right)$, reserve the first $m$ common components.
Step 5. Rotate the load matrix $\wedge$ and the common factors matrix $F$. Obtain the rotated common factor matrix $\widetilde{F}$ and the load matrix $B$, where $B=\wedge Q$, $\widetilde{F}=Q^{T} F$, and $Q$ is an orthogonal matrix that maximizes the variance of $\wedge$.

Step 6. Based on the load matrix $B$, calculate the score coefficient matrix $E=\left(B^{T} D^{-1} B\right)^{-1} B^{T} D^{-1}$, where $D=\operatorname{diag}\left(\sigma_{1}^{-2}, \sigma_{2}^{-2}, \ldots, \sigma_{p}^{-2}\right)$, and $\sigma_{j}^{2}$ is the variance of the special factor $\theta_{j}$.

$$
E=\left[\begin{array}{ccc}
e_{11} & \ldots & e_{1 m} \\
\vdots & \ddots & \vdots \\
e_{p 1} & \cdots & e_{p m}
\end{array}\right]
$$

Step 7. Based on the score coefficient matrix $E$, calculate the normalized score coefficient matrix $E^{\prime}=\left(e_{j o}^{\prime \prime}\right)_{p \times m}$. In real problems, there are always some negative numbers $e_{j o}<0$ in the score coefficient vector $e_{o}=\left(e_{1 o}, e_{2 o}, \ldots, e_{p o}\right), \quad(j=1,2, \ldots, p ; o=1,2, \ldots$, $m)$. To address these problems, we transform eo.

If the original variable $\xi_{j}\left(e_{j o}<0\right)$ has a smaller factor loading on $\widetilde{F}_{O}$,

$$
e_{j o}^{\prime}=e_{j o}-\min \left(e_{j o}\right) .
$$

If the original variable $\xi_{j}\left(e_{j o}<0\right)$ has a larger factor loading on $\widetilde{F}_{O}$,

$$
e_{j o}^{\prime}=\max \left(e_{j o}\right)-e_{j o},
$$

then $e_{j o}^{\prime \prime}=\left(e_{j o}^{\prime} / \sum_{j=1}^{p} e_{j o}^{\prime}\right)$ and $E^{\prime}=\left(e_{j o}^{\prime \prime}\right)_{p \times m}$.

Step 8. Calculate the score matrix $S, S=\xi E^{\prime}$ :

$$
S=\left[\begin{array}{ccc}
s_{11} & \ldots & s_{1 m} \\
\vdots & \ddots & \vdots \\
s_{p 1} & \cdots & s_{p m}
\end{array}\right]
$$

\section{Case Study}

4.1. Project Overview. With the rapid development of industry and increasing numbers of people and vehicles, problems caused by traffic jams and pollution are getting worse. Therefore, the government of Tianjin would like to promote the construction of an urban rail transit system to alleviate these problems. As of December 2018, there were 6 lines (Line 1, Line 2, Line 3, Line 5, Line 6, and Line 9) with a total length of $219 \mathrm{~km}$. The Tianjin urban rail transit limited liability company (Tianjin Metro) is responsible for different functions, including rail transit planning, investment, financing, implementation management, operations management, management, and development. At present, the procurement of materials in the operation stage for the Tianjin urban rail transit is uniformly performed by the relevant departments, gaining certain scale benefits.

The urban rail transit system is complex, including ticket autosale systems, elevator systems, screen door systems, 
illumination systems, environmental control systems, and water supply and draining systems. Equipment is an important part of this system. It plays a very important role in the construction and subsequent operations of the subway. The investment in equipment accounts for $70 \%$ of the total investment of subway projects. It also has the characteristics of high quality, high technology, and high reliability. In addition, some equipment has poor universality and compatibility attributes due to brand protection. This results in the models of the equipment in the same system being different.

Currently, when the purchased money of materials is between a half million RMB and 2 million RMB, Tianjin urban rail transit uses the comparative method to select suppliers; when the purchased money of materials exceeds 2 million $\mathrm{RMB}$, the urban rail transit company uses public bidding to select suppliers. During the evaluation process, the staff of the operation centre and external experts score the bids together. Finally, the results are based on simple weighted averages. The indicators include credit (10\%), technology (30\%), and business (60\%). This method is easy to understand and highly operable.

The advantage of this method is easy to understand and operate. The disadvantage is that there may be black box operation. Moreover, when using the inquiry ratio procurement method or the public bidding method for supplier selection, the final selection result is mostly the supplier which has the lowest price. However, the following problems often occur in the subsequent execution of the contract: (1) when the company reviewing the bid-winning supplier, it usually finds that its scale is small and the quality of equipment is relatively average. (2) During the bidding process, the supplier gives much low price. After signing the contract, it does not actively implement the contract, delaying the delivery time to let the company increase price or reducing equipment quality to save costs.

However, supplier selection is a complex decisionmaking problem. The incomplete evaluation value, various personal preferences, lots of indicators with overlapping effects, and random environment all affect the results. To solve these problems, this paper uses an intuitionistic fuzzy factor analysis model under a random environment. This model effectively resolves the overlapping effects between indicators and considers random environments. This model is also used to determine some common factors with good interpretability for suppliers. The suppliers are selected and sorted by calculating the score of the factors.

4.2. Building the Indicator System. The equipment suppliers of urban rail transit are different from those of traditional industries. The need for equipment with high-quality and a timely and stable supply determines which suppliers are eligible based on the following characteristics:

(1) In terms of high quality, the use of urban rail transit equipment necessitates high-quality requirements

(2) In terms of high reliability, reliability defines the capability to supply equipment in a timely and dependable manner under specific conditions and within a limited time period

(3) In terms of unconventionality, there are many kinds of urban rail transit equipment that cover a wide range of applications, so the equipment has great variety and low volume to reduce the management costs and form economies of scale

(4) In terms of the supply cycle, shorter supply cycles will reduce the risks of supply disruption and the tying-up of funds

(5) For high technology, the supplier must be able to meet new equipment needs or improve existing accessories

(6) Price has always been an important criterion for evaluating suppliers

The determination of supplier evaluation indicators plays an important role in selecting the appropriate suppliers. With the development of society, companies have paid increasing attention to indicators such as environmental friendliness, social responsibility, and customer satisfaction. Considering the characteristics of subway equipment, this paper combines the relevant literature of the supplier evaluation index system and selects representative indicators from it. Then communicating with relevant experts, we get the final evaluation indicators system of subway equipment suppliers. And we organize it into Table 1.

4.3. Supplier Selection. In this paper, five suppliers $\left(A_{1}, A_{2}, A_{3}, A_{4}, A_{5}\right)$ were selected as alternatives from a 2019 list of Tianjin urban rail transit equipment suppliers.

Three groups of experts from Tianjin urban rail transit evaluated the alternatives. Tables $2-4$ are the decision matrix obtained from each group of experts. For example, expert group 1 invited 10 experts to evaluate the indicators of these 5 suppliers. For attribute $C_{2}$ for company $A_{1}$, if seven experts think $C_{2}$ is strong, two experts think $C_{2}$ is weak, and one expert cannot judge whether $C_{2}$ is strong or weak, then the evaluation value of $A_{1}$ for attribute $C_{2}$ will be the intuitive fuzzy number $(0.7,0.2)$. A comprehensive intuitionistic fuzzy decision matrix is shown in Table 5 according to Tables 2-4.

In this paper, we assume that the alternatives are affected by two environmental factors: the economy environment $Y_{1}\left(Y_{1} \in[-1,1]\right)$ and policy environment $Y_{2}\left(Y_{2} \in\right.$ $[-1,1]) . Y_{1} \in(0,1]$ indicates that the economy is heated, and $Y_{1} \in[-1,0)$ indicates that the economy is depressed. $Y_{2} \in(0,1]$ indicates that the policy plays a positive role, while $Y_{2} \in[-1,0)$ indicates that the policy plays a negative role. $Y_{1}=Y_{2}=0$ indicates that the alternatives are not affected by these factors. It is assumed that two environmental factors have the same effect on the alternatives, such as $\alpha_{i j}=\alpha_{j}(y)$. Indicators $C_{1}-C_{6}$ are positively affected by $Y_{2}$, and indicators $C_{7}-C_{9}$ are negatively affected by $Y_{1}$. That is, the policy has a positive effect on $C_{1}-C_{6}$, and rapid economic development is conducive to reducing the price of the rejection rate and the inability to meet future requirements for products. 
TABLE 1: Evaluation indicators for suppliers of urban rail transit.

\begin{tabular}{lc}
\hline Indicator & References \\
\hline Quality & {$[27,35-40]$} \\
Technology & {$[27,35,37-40]$} \\
Delivery & {$[27,37-40]$} \\
Response & {$[29]$} \\
Comprehensive strength & {$[28,39]$} \\
Willingness & {$[27,37]$} \\
Price & {$[28,37-40]$} \\
Rejection rate & {$[27,39]$} \\
Inability to meet future requirements & {$[27,38]$} \\
\hline
\end{tabular}

The defined distribution function is as follows:

$$
\begin{aligned}
& \alpha_{i 1}(y)=\left(1+Y_{2}\right) \alpha_{i 1}=\left(1-\left(1-u_{i 1}\right)^{1+Y_{2}}, v_{i 1}^{1+Y_{2}}\right), \\
& \alpha_{i 2}(y)=\left(1+Y_{2}\right) \alpha_{i 2}=\left(1-\left(1-u_{i 2}\right)^{1+Y_{2}}, v_{i 2}^{1+Y_{2}}\right), \\
& \alpha_{i 3}(y)=\left(1+Y_{2}\right) \alpha_{i 3}=\left(1-\left(1-u_{i 3}\right)^{1+Y_{2}}, v_{i 3}^{1+Y_{2}}\right), \\
& \alpha_{i 4}(y)=\left(1+Y_{2}\right) \alpha_{i 4}=\left(1-\left(1-u_{i 4}\right)^{1+Y_{2}}, v_{i 4}^{1+Y_{2}}\right), \\
& \alpha_{i 5}(y)=\left(1+Y_{2}\right) \alpha_{i 5}=\left(1-\left(1-u_{i 5}\right)^{1+Y_{2}}, v_{i 5}^{1+Y_{2}}\right), \\
& \alpha_{i 6}(y)=\left(1+Y_{2}\right) \alpha_{i 6}=\left(1-\left(1-u_{i 6}\right)^{1+Y_{2}}, v_{i 6}^{1+Y_{2}}\right), \\
& \alpha_{i 7}(y)=\left(1-Y_{1}\right) \alpha_{i 7}=\left(1-\left(1-u_{i 1}\right)^{1-Y_{1}}, v_{i 7}^{1-Y_{1}}\right), \\
& \alpha_{i 8}(y)=\left(1-Y_{1}\right) \alpha_{i 8}=\left(1-\left(1-u_{i 8}\right)^{1-Y_{1}}, v_{i 8}^{1-Y_{1}}\right), \\
& \alpha_{i 9}(y)=\left(1-Y_{1}\right) \alpha_{i 9}=\left(1-\left(1-u_{i 9}\right)^{1-Y_{1}}, v_{i 9}^{1-Y_{1}}\right) .
\end{aligned}
$$

Then select alternatives according to the model built in Section 3. The calculation steps are as follows: :

Step 1. Based on the comprehensive intuitionistic fuzzy decision matrix, use the environment distribution function defined above to obtain the comprehensive intuitionistic fuzzy decision matrix under random environment, as shown in Table 6.

Step 2. According to the random intuitionistic fuzzy decision matrix and Definition 7 , the correlation matrix of the indicators is calculated in Table 7.

Step 3. Based on the correlation coefficient matrix, Table 8 is obtained. According to the selection criteria (an eigenvalue larger than 1 and a cumulative contribution rate higher than 90\%), we can extract two common factors.

Step 4. The factor load matrix is rotated to obtain Table 9 The factor loads in Table 9 indicate that the results are reliable. The factor loads of attributes $C_{1}-$ $C_{6}$ for factor 1 are higher than 0.85 . These attributes are related to the urban rail transit company itself. The factor loads of attributes $C_{7}-C_{9}$ for factor 2 are higher than 0.80 . These factors are greatly affected by external factors. Finally, according to formula (16), the weights of the two factors are calculated as $\omega=(0.8657,0.1353)$.

Step 5. The score coefficient matrix is calculated to produce Table 10. Then, Table 10 is normalized to obtain Table 11.

Step 6. Letting $Y_{1}=Y_{2}=0$, according to Table 11, the score of the two factors is summarized to obtain Table 12.

Step 7. Based on Table 12 and Definition 3, we rank the alternatives in Table 13. After scoring the suppliers, the final ranking result is $A_{5}>A_{1}>, A_{4}>A_{2}>A_{3} \cdot A_{5}$ is the electromechanical equipment supplier that is the best choice for Tianjin urban rail transit.

Step 8. By changing the values of $Y_{1}$ and $Y_{2}$, we recalculate the scores of the two factors to obtain the comprehensive scores of the alternatives under different environmental conditions in Tables 14-17, where $Y_{1}=-0.5$ means that the economy is recovering, while $Y_{1}=-0.5$ means that the economy is declining. $Y_{2}=$ 0.5 means that the policy is playing a positive role, while $Y_{1}=-0.5$ means that the policy is playing a negative role.

The data in Tables 13 to 17 show that when environmental factors change, the score and ranks of suppliers will change.

(1) When $Y_{2}=-05$, regardless of the state of the economic environment, the supplier's scores appear negative. Therefore, there is a conclusion: the technological environment has an influence on subway equipment suppliers.

(2) When $Y_{1}=-0.5$ and $Y_{2}=-0.5 ; Y_{1}=0.5$ and $Y_{2}=0.5$; $Y_{1}=0.5$ and $Y_{2}=-0.5$; or $Y_{1}=0$ and $Y_{2}=-0.5$, the company's optimal supplier changes from $A_{5}$ to $A_{1}$. The reason for this phenomenon is that $A_{1}$ is more sensitive to the change of environment. When environmental factors change, the score of $A_{1}$ increases more or the score decreases more, so the optimal solution is $A_{1}$.

(3) When $Y_{1}=0.5, Y_{2}=0.5$, the overall score of the supplier has risen, the overall performance of the supplier becomes better, and the difference between the suppliers gradually shrinks.

To sum up, the subway company must consider the impact of environmental changes when selecting equipment suppliers. The optimal solution under different decisionmaking environments is different, and there may even be a situation where all suppliers' scores are negative. In this extreme situation, the company can even reselect alternative suppliers for reevaluation until a choice that meets the company's decision is selected. 
TABLE 2: Intuitionistic fuzzy decision matrix of $\mathrm{EG}_{1}$.

\begin{tabular}{cccccccccc}
\hline & $\mathrm{C}_{1}$ & $\mathrm{C}_{2}$ & $\mathrm{C}_{3}$ & $\mathrm{C}_{4}$ & $\mathrm{C}_{5}$ & $\mathrm{C}_{6}$ & $\mathrm{C}_{7}$ & $\mathrm{C}_{8}$ & $\mathrm{C}_{9}$ \\
\hline $\mathrm{A}_{1}$ & $(0.8,0.2)$ & $(0.7,0.1)$ & $(0.8,0.1)$ & $(0.7,0.1)$ & $(0.6,0.3)$ & $(0.7,0.2)$ & $(0.1,0.8)$ & $(0.2,0.7)$ & $(0.2,0.7)$ \\
$\mathrm{A}_{2}$ & $(0.7,0.2)$ & $(0.4,0.5)$ & $(0.6,0.3)$ & $(0.6,0.3)$ & $(0.5,0.3)$ & $(0.6,0.3)$ & $(0.5,0.3)$ & $(0.4,0.3)$ & $(0.3,0.6)$ \\
$\mathrm{A}_{3}$ & $(0.3,0.5)$ & $(0.6,0.3)$ & $(0.7,0.2)$ & $(0.6,0.2)$ & $(0.5,0.4)$ & $(0.6,0.2)$ & $(0.4,0.5)$ & $(0.5,0.5)$ & $(0.5,0.4)$ \\
$\mathrm{A}_{4}$ & $(0.7,0.2)$ & $(0.7,0.2)$ & $(0.7,0.1)$ & $(0.7,0.2)$ & $(0.5,0.2)$ & $(0.4,0.5)$ & $(0.2,0.7)$ & $(0.6,0.3)$ & $(0.3,0.5)$ \\
$\mathrm{A}_{5}$ & $(0.8,0.1)$ & $(0.8,0.1)$ & $(0.8,0.2)$ & $(0.8,0.2)$ & $(0.7,0.1)$ & $(0.8,0.1)$ & $(0.1,0.8)$ & $(0.8,0.1)$ & $(0.1,0.8)$ \\
\hline
\end{tabular}

TABLE 3: Intuitionistic fuzzy decision matrix of $\mathrm{EG}_{2}$.

\begin{tabular}{cccccccccc}
\hline & $\mathrm{C}_{1}$ & $\mathrm{C}_{2}$ & $\mathrm{C}_{3}$ & $\mathrm{C}_{4}$ & $\mathrm{C}_{5}$ & $\mathrm{C}_{6}$ & $\mathrm{C}_{7}$ & $\mathrm{C}_{8}$ & $\mathrm{C}_{9}$ \\
\hline $\mathrm{A}_{1}$ & $(0.8,0.1)$ & $(0.8,0.1)$ & $(0.7,0.2)$ & $(0.8,0.1)$ & $(0.7,0.2)$ & $(0.8,0.1)$ & $(0.2,0.7)$ & $(0.1,0.8)$ & $(0.2,0.7)$ \\
$\mathrm{A}_{2}$ & $(0.6,0.3)$ & $(0.5,0.4)$ & $(0.5,0.3)$ & $(0.5,0.3)$ & $(0.5,0.2)$ & $(0.6,0.2)$ & $(0.5,0.4)$ & $(0.6,0.3)$ & $(0.3,0.6)$ \\
$\mathrm{A}_{3}$ & $(0.4,0.5)$ & $(0.5,0.3)$ & $(0.6,0.3)$ & $(0.6,0.3)$ & $(0.4,0.4)$ & $(0.6,0.2)$ & $(0.3,0.5)$ & $(0.3,0.6)$ & $(0.4,0.5)$ \\
$\mathrm{A}_{4}$ & $(0.6,0.2)$ & $(0.6,0.3)$ & $(0.7,0.1)$ & $(0.6,0.2)$ & $(0.6,0.2)$ & $(0.3,0.6)$ & $(0.2,0.6)$ & $(0.2,0.6)$ & $(0.3,0.5)$ \\
$\mathrm{A}_{5}$ & $(0.8,0.2)$ & $(0.7,0.1)$ & $(0.8,0.2)$ & $(0.7,0.2)$ & $(0.8,0.1)$ & $(0.7,0.3)$ & $(0.1,0.7)$ & $(0.1,0.7)$ & $(0.2,0.6)$ \\
\hline
\end{tabular}

TABLE 4: Intuitionistic fuzzy decision matrix of $\mathrm{EG}_{3}$.

\begin{tabular}{lccccccccc}
\hline & $\mathrm{C}_{1}$ & $\mathrm{C}_{2}$ & $\mathrm{C}_{3}$ & $\mathrm{C}_{4}$ & $\mathrm{C}_{5}$ & $\mathrm{C}_{6}$ & $\mathrm{C}_{7}$ & $\mathrm{C}_{8}$ & $\mathrm{C}_{9}$ \\
\hline $\mathrm{A}_{1}$ & $(0.7,0.2)$ & $(0.7,0.2)$ & $(0.7,0.2)$ & $(0.7,0.2)$ & $(0.6,0.3)$ & $(0.7,0.1)$ & $(0.2,0.8)$ & $(0.3,0.6)$ & $(0.2,0.8)$ \\
$\mathrm{A}_{2}$ & $(0.5,0.3)$ & $(0.4,0.5)$ & $(0.5,0.3)$ & $(0.5,0.3)$ & $(0.5,0.3)$ & $(0.5,0.3)$ & $(0.4,0.5)$ & $(0.4,0.4)$ & $(0.3,0.5)$ \\
$\mathrm{A}_{3}$ & $(0.3,0.5)$ & $(0.4,0.5)$ & $(0.4,0.5)$ & $(0.4,0.3)$ & $(0.4,0.4)$ & $(0.6,0.3)$ & $(0.3,0.5)$ & $(0.5,0.3)$ & $(0.4,0.4)$ \\
$\mathrm{A}_{4}$ & $(0.4,0.5)$ & $(0.5,0.4)$ & $(0.6,0.3)$ & $(0.6,0.3)$ & $(0.6,0.3)$ & $(0.4,0.5)$ & $(0.2,0.7)$ & $(0.3,0.6)$ & $(0.4,0.5)$ \\
$\mathrm{A}_{5}$ & $(0.6,0.3)$ & $(0.6,0.2)$ & $(0.7,0.2)$ & $(0.7,0.2)$ & $(0.8,0.1)$ & $(0.8,0.1)$ & $(0.3,0.6)$ & $(0.1,0.8)$ & $(0.1,0.8)$ \\
\hline
\end{tabular}

TABLe 5: Comprehensive intuitionistic fuzzy decision matrix.

\begin{tabular}{|c|c|c|c|c|c|c|c|c|c|}
\hline & $\mathrm{C}_{1}$ & $\mathrm{C}_{2}$ & $\mathrm{C}_{3}$ & $\mathrm{C}_{4}$ & $\mathrm{C}_{5}$ & $\mathrm{C}_{6}$ & $\mathrm{C}_{7}$ & $\mathrm{C}_{8}$ & $\mathrm{C}_{9}$ \\
\hline $\mathrm{A}_{1}$ & $\begin{array}{c}(0.7667 \\
0.1667)\end{array}$ & $\begin{array}{c}(0.7333 \\
0.1333)\end{array}$ & $\begin{array}{c}(0.7333 \\
0.1667)\end{array}$ & $\begin{array}{c}(0.7333 \\
0.1333)\end{array}$ & $\begin{array}{l}(0.6333 \\
0.2667)\end{array}$ & $\begin{array}{c}(0.7333 \\
0.1333)\end{array}$ & $\begin{array}{l}(0.1667 \\
0.7667)\end{array}$ & $(0.2,0.7)$ & $(0.2,0.7333)$ \\
\hline $\mathrm{A}_{2}$ & $(0.6,0.2667)$ & $\begin{array}{l}(0.4333 \\
0.4667)\end{array}$ & $(0.5333,0.3)$ & $(0.5333,0.3)$ & $(0.5,0.2667)$ & $\begin{array}{l}(0.5667 \\
0.2667)\end{array}$ & $(0.4667,0.4)$ & $(0.5,0.3667)$ & $(0.3,0.5667)$ \\
\hline $\mathrm{A}_{3}$ & $(0.3333,0.5)$ & $(0.5,0.3667)$ & $\begin{array}{l}(0.5667 \\
0.3333)\end{array}$ & $\begin{array}{l}(0.5333 \\
0.2667)\end{array}$ & $(0.4333,0.4)$ & $(0.6,0.2333)$ & $(0.3333,0.5)$ & $\begin{array}{l}(0.3667 \\
0.4667)\end{array}$ & $\begin{array}{l}(0.4333 \\
0.4333)\end{array}$ \\
\hline $\mathrm{A}_{4}$ & $(0.5667,0.3)$ & $(0.6,0.3)$ & $\begin{array}{c}(0.6667 \\
0.1667)\end{array}$ & $\begin{array}{l}(0.6333 \\
0.2333)\end{array}$ & $\begin{array}{l}(0.5667 \\
0.2333)\end{array}$ & $\begin{array}{l}(0.3667 \\
0.5333)\end{array}$ & $(0.2,0.6667)$ & $(0.2667,0.6)$ & $(0.3333,0.5)$ \\
\hline $\mathrm{A}_{5}$ & $(0.7333,0.2)$ & $(0.7,0.1333)$ & $(0.7667,0.2)$ & $(0.7333,0.2)$ & $(0.7667,0.1)$ & $\begin{array}{c}(0.7667 \\
0.1667)\end{array}$ & $(0.1667,0.7)$ & $(0.1,0.7667)$ & $\begin{array}{l}(0.1333, \\
0.7333)\end{array}$ \\
\hline
\end{tabular}

TABLE 6: Random intuitionistic fuzzy decision matrix.

\begin{tabular}{|c|c|c|c|c|c|c|}
\hline & $\mathrm{A}_{1}$ & $\mathrm{~A}_{2}$ & $\mathrm{~A}_{3}$ & $\mathrm{~A}_{4}$ & $\mathrm{~A}_{5}$ & Sample mean \\
\hline $\mathrm{C}_{1}$ & $\begin{array}{l}\left(0.2333^{1+\mathrm{Y} 2},\right. \\
\left.0.1667^{1+\mathrm{Y} 2}\right)\end{array}$ & $\left(0.4^{1+\mathrm{Y} 2}, 0.2667^{1+\mathrm{Y} 2}\right)$ & $\left(0.6667^{1+Y 2}, 0.5^{1+Y 2}\right)$ & $\left(0.4333^{1+Y 2}, 0.3^{1+Y 2}\right)$ & $\left(0.2667^{1+\mathrm{Y} 2}, 0.2^{1+\mathrm{Y} 2}\right)$ & $\begin{array}{l}\left(0.3727^{1+Y 2},\right. \\
\left.0.2661^{1+Y 2}\right)^{\prime}\end{array}$ \\
\hline $\mathrm{C}_{2}$ & $\begin{array}{l}\left(0.2667^{1+\mathrm{Y} 2},\right. \\
\left.0.1333^{1+\mathrm{Y} 2}\right)\end{array}$ & $\begin{array}{c}\left(0.5667^{1+Y 2}\right. \\
\left.0.4667^{1+Y 2}\right)\end{array}$ & $\left(0.5^{1+\mathrm{Y} 2}, 0.3667^{1+\mathrm{Y} 2}\right)$ & $\left(0.4^{1+\mathrm{Y} 2}, 0.3^{1+\mathrm{Y} 2}\right)$ & $\left(0.3^{1+\mathrm{Y} 2}, 0.1333^{1+\mathrm{Y} 2}\right)$ & $\begin{array}{l}\left(0.3904^{1+\mathrm{Y} 2},\right. \\
\left.0.2466^{1+\mathrm{Y} 2}\right)\end{array}$ \\
\hline $\mathrm{C}_{3}$ & $\begin{array}{l}\left(0.2667^{1+Y^{\prime}},\right. \\
\left.0.1667^{1+Y 2}\right)^{\prime}\end{array}$ & $\left(0.4667^{1+Y 2}, 0.3^{1+Y 2}\right)$ & $\begin{array}{c}\left(0.4333^{1+Y 2}\right. \\
\left.0.3333^{1+Y 2}\right)\end{array}$ & $\begin{array}{c}\left(0.3333^{1+Y 2}\right. \\
\left.0.1667^{1+Y 2}\right)\end{array}$ & $\left(0.2333^{1+\mathrm{Y} 2}, 0.2^{1+\mathrm{Y} 2}\right)$ & $\begin{array}{l}\left(0.3346^{1+\mathrm{Y} 2},\right. \\
\left.0.2233^{1+\mathrm{Y} 2}\right)^{\prime}\end{array}$ \\
\hline $\mathrm{C}_{4}$ & $\begin{array}{l}\left(0.2667^{1+Y 2},\right. \\
\left.0.1333^{1+Y 2}\right)\end{array}$ & $\left(0.4667^{1+Y 2}, 0.3^{1+Y 2}\right)$ & $\begin{array}{l}\left(0.4667^{1+Y 2}\right. \\
\left.0.2667^{1+Y 2}\right)\end{array}$ & $\begin{array}{l}\left(0.3667^{1+\mathrm{Y} 2},\right. \\
\left.0.2333^{1+\mathrm{Y} 2}\right)\end{array}$ & $\left(0.2667^{1+\mathrm{Y} 2}, 0.2^{1+\mathrm{Y} 2}\right)$ & $\begin{array}{l}\left(0.3555^{1+\mathrm{Y} 2},\right. \\
\left.0.2185^{1+\mathrm{Y} 2}\right)\end{array}$ \\
\hline $\mathrm{C}_{5}$ & $\begin{array}{l}\left(0.3667^{1+\mathrm{Y} 2},\right. \\
\left.0.2667^{1+\mathrm{Y} 2}\right)\end{array}$ & $\left(0.5^{1+\mathrm{Y} 2}, 0.2667^{1+\mathrm{Y} 2}\right)$ & $\left(0.5667^{1+\mathrm{Y} 2}, 0.4^{1+\mathrm{Y} 2}\right)$ & $\begin{array}{l}\left(0.4333^{1+\mathrm{Y} 2},\right. \\
\left.0.2333^{1+\mathrm{Y} 2}\right)\end{array}$ & $\left(0.2333^{1+\mathrm{Y} 2}, 0.1^{1+\mathrm{Y} 2}\right)$ & $\begin{array}{l}\left(0.4020^{1+\mathrm{Y} 2},\right. \\
\left.0.2314^{1+\mathrm{Y} 2}\right)^{\prime}\end{array}$ \\
\hline $\mathrm{C}_{6}$ & $\begin{array}{l}\left(0.2667^{1+Y 2},\right. \\
\left.0.1333^{1+Y 2}\right)\end{array}$ & $\begin{array}{c}\left(0.4333^{1+Y 2}\right. \\
\left.0.2667^{1+Y 2}\right)\end{array}$ & $\left(0.4^{1+\mathrm{Y} 2}, 0.2333^{1+\mathrm{Y} 2}\right)$ & $\begin{array}{l}\left(0.6333^{1+\mathrm{Y} 2},\right. \\
\left.0.5333^{1+\mathrm{Y} 2}\right)\end{array}$ & $\begin{array}{c}\left(0.2333^{1+\mathrm{Y} 2}\right. \\
\left.0.1667^{1+\mathrm{Y} 2}\right)\end{array}$ & $\begin{array}{l}\left(0.3689^{1+\mathrm{Y} 2},\right. \\
\left.0.2363^{1+\mathrm{Y} 2}\right)\end{array}$ \\
\hline $\mathrm{C}_{7}$ & $\begin{array}{l}\left(0.8333^{1-Y 1},\right. \\
\left.0.7667^{1-Y 1}\right)\end{array}$ & $\left(0.5333^{1-Y 1}, 0.4^{1-Y 1}\right)$ & $\left(0.6667^{1-Y 1}, 0.5^{1-Y 1}\right)$ & $\left(0.8^{1-\mathrm{Y} 1}, 0.6667^{1-\mathrm{Y} 1}\right)$ & $\left(0.8333^{1-\mathrm{Y} 1}, 0.7^{1-\mathrm{Y} 1}\right)$ & $\begin{array}{l}\left(0.7230^{1+\mathrm{Y} 2},\right. \\
\left.0.5901^{1+\mathrm{Y} 2}\right)^{\prime}\end{array}$ \\
\hline $\mathrm{C}_{8}$ & $\left(0.8^{1-\mathrm{Y} 1}, 0.7^{1-\mathrm{Y} 1}\right)$ & $\left(0.5^{1-Y 1}, 0.3667^{1-Y 1}\right)$ & $\begin{array}{l}\left(0.6333^{1-\mathrm{Y} 1}\right. \\
\left.0.4667^{1-\mathrm{Y} 1}\right)\end{array}$ & $\left(0.7333^{1-\mathrm{Y} 1}, 0.6^{1-\mathrm{Y} 1}\right)$ & $\left(0.9^{1-\mathrm{Y} 1}, 0.7667^{1-\mathrm{Y} 1}\right)$ & $\begin{array}{l}\left(0.6993^{1+\mathrm{Y} 2},\right. \\
\left.0.5601^{1+\mathrm{Y} 2}\right)^{\prime}\end{array}$ \\
\hline $\mathrm{C}_{9}$ & $\left(0.8^{1-\mathrm{Y} 1}, 0.7333^{1-\mathrm{Y} 1}\right)$ & $\left(0.7^{1-\mathrm{Y} 1}, 0.5667^{1-\mathrm{Y} 1}\right)$ & $\begin{array}{l}\left(0.5667^{1-\mathrm{Y} 1},\right. \\
\left.0.4333^{1-\mathrm{Y} 1}\right)\end{array}$ & $\left(0.6667^{1-\mathrm{Y} 1}, 0.5^{1-\mathrm{Y} 1}\right)$ & $\begin{array}{l}\left(0.8667^{1-\mathrm{Y} 1}\right. \\
\left.0.7333^{1-\mathrm{Y} 1}\right)\end{array}$ & $\begin{array}{l}\left(0.7123^{1+\mathrm{Y} 2},\right. \\
\left.0.5807^{1+\mathrm{Y} 2}\right)\end{array}$ \\
\hline
\end{tabular}


TABLE 7: Correlation matrix of indicators.

\begin{tabular}{|c|c|c|c|c|c|c|c|c|c|}
\hline & $\mathrm{C}_{1}$ & $\mathrm{C}_{2}$ & $\mathrm{C}_{3}$ & $\mathrm{C}_{4}$ & $\mathrm{C}_{5}$ & $\mathrm{C}_{6}$ & $\mathrm{C}_{7}$ & $\mathrm{C}_{8}$ & $\mathrm{C}_{9}$ \\
\hline $\mathrm{C}_{1}$ & 1 & & & & & & & & \\
\hline $\mathrm{C}_{2}$ & 0.9708 & 1 & & & & & & & \\
\hline $\mathrm{C}_{3}$ & 0.9720 & 0.9886 & 1 & & & & & & \\
\hline $\mathrm{C}_{4}$ & 0.9762 & 0.9911 & 0.9980 & 1 & & & & & \\
\hline $\mathrm{C}_{5}$ & 0.9718 & 0.9715 & 0.9821 & 0.9769 & 1 & & & & \\
\hline $\mathrm{C}_{6}$ & 0.9425 & 0.9510 & 0.9407 & 0.9565 & 0.9402 & 1 & & & \\
\hline $\mathrm{C}_{7}$ & 0.6389 & 0.5676 & 0.6588 & 0.6676 & 0.6449 & 0.6919 & 1 & & \\
\hline $\mathrm{C}_{8}$ & 0.6346 & 0.5676 & 0.6618 & 0.6701 & 0.6278 & 0.6700 & 0.9929 & 1 & \\
\hline $\mathrm{C}_{9}$ & 0.6211 & 0.6729 & 0.7502 & 0.7462 & 0.6761 & 0.6818 & 0.8360 & 0.8630 & 1 \\
\hline
\end{tabular}

TABLE 8: Eigenvalues and cumulative contribution rates of common factors.

\begin{tabular}{lccc}
\hline$m=2$ & Factor 1 & Factor 2 & Factor 3 \\
\hline SS loadings & 7.5021 & 1.1641 & 0.2301 \\
Proportion var & 0.8336 & 0.1293 & 0.0256 \\
Cumulative var & 0.8336 & 0.9629 & 0.9885 \\
\hline
\end{tabular}

TABle 9: Factor loadings and communities of extracted factors.

\begin{tabular}{lccr}
\hline Indicator & Factor 1 & Factor 2 & $h^{2}$ \\
\hline $\mathrm{C}_{1}$ & 0.9248 & 0.3369 & 0.97 \\
$\mathrm{C}_{2}$ & 0.9543 & 0.2877 & 0.99 \\
$\mathrm{C}_{3}$ & 0.9099 & 0.4028 & 0.99 \\
$\mathrm{C}_{4}$ & 0.9104 & 0.4084 & 1.00 \\
$\mathrm{C}_{5}$ & 0.9200 & 0.3563 & 0.97 \\
$\mathrm{C}_{6}$ & 0.8754 & 0.4129 & 0.94 \\
$\mathrm{C}_{7}$ & 0.3304 & 0.9255 & 0.97 \\
$\mathrm{C}_{8}$ & 0.3194 & 0.9380 & 0.98 \\
$\mathrm{C}_{9}$ & 0.4301 & 0.8220 & 0.86 \\
\hline
\end{tabular}

TABLE 10: Score coefficients of extracted factors.

\begin{tabular}{lccccccccc}
\hline & $\mathrm{C}_{1}$ & $\mathrm{C}_{2}$ & $\mathrm{C}_{3}$ & $\mathrm{C}_{4}$ & $\mathrm{C}_{5}$ & $\mathrm{C}_{6}$ & $\mathrm{C}_{7}$ & $\mathrm{C}_{8}$ & $\mathrm{C}_{9}$ \\
\hline Factor 1 & 0.4009 & 1.2944 & -0.0771 & -0.0629 & 0.0985 & -0.5415 & -0.0982 & -0.1571 & -0.0293 \\
Factor 2 & -0.3964 & -2.4954 & 0.3829 & 0.2895 & 0.0609 & 2.0874 & 0.2602 & 0.4162 & 0.0782 \\
\hline
\end{tabular}

TABLE 11: Normalized score coefficients of extracted factors.

\begin{tabular}{lccccccrrr}
\hline & $\mathrm{C}_{1}$ & $\mathrm{C}_{2}$ & $\mathrm{C}_{3}$ & $\mathrm{C}_{4}$ & $\mathrm{C}_{5}$ & $\mathrm{C}_{6}$ & $\mathrm{C}_{7}$ & $\mathrm{C}_{8}$ & $\mathrm{C}_{9}$ \\
\hline Factor 1 & 0.1653 & 0.3220 & 0.0815 & 0.0840 & 0.1123 & 0 & 0.0778 & 0.0674 & 0.0898 \\
Factor 2 & 0.0907 & 0 & 0.1244 & 0.1203 & 0.1105 & 0.1980 & 0.1191 & 0.1258 & 0.1112 \\
\hline
\end{tabular}

TABLE 12: Scores of common factors when $Y_{1}=Y_{2}=0$.

\begin{tabular}{lcrr}
\hline & Factor 1 & Factor 2 & Comprehensive factor \\
\hline $\mathrm{A}_{1}$ & $(0.6489,0.2274)$ & $(0.5945,0.2770)$ & $(0.6971,0.2335)$ \\
$\mathrm{A}_{2}$ & $(0.4862,0.3674)$ & $(0.5101,0.3260)$ & $(0.5211,0.3615)$ \\
$\mathrm{A}_{3}$ & $(0.4509,0.3980)$ & $(0.4757,0.3608)$ & $(0.4810,0.3928)$ \\
$\mathrm{A}_{4}$ & $(0.5396,0.3178)$ & $(0.4657,0.3745)$ & $(0.5632,0.3249)$ \\
$\mathrm{A}_{5}$ & $(0.6441,0.2202)$ & $(0.6170,0.2838)$ & $(0.6975,0.2279)$ \\
\hline
\end{tabular}

TABLE 13: Scores of alternatives when $Y_{1}=Y_{2}=0$.

\begin{tabular}{lccc}
\hline & Factor 1 & Factor 2 & Comprehensive factor \\
\hline $\mathrm{A}_{1}$ & 0.4215 & 0.3175 & 0.4636 \\
$\mathrm{~A}_{2}$ & 0.1188 & 0.1840 & 0.1596 \\
$\mathrm{~A}_{3}$ & 0.0529 & 0.1148 & 0.0882 \\
$\mathrm{~A}_{4}$ & 0.2218 & 0.0911 & 0.2384 \\
$\mathrm{~A}_{5}$ & 0.4239 & 0.3332 & 0.4696 \\
\hline
\end{tabular}


TABLE 14: Scores of alternatives when $Y_{1}=0$.

\begin{tabular}{ccccccc}
\hline & \multicolumn{2}{c}{$Y 1=0$} & & & \\
& \multicolumn{3}{c}{$Y_{2}=0.5$} & & & $Y_{2}=-0.5$ \\
& Factor 1 & Factor 2 & Comprehensive factor & Factor 1 & Factor 2 & Comprehensive factor \\
\hline $\mathrm{A}_{1}$ & 0.6743 & 0.5779 & 0.7561 & -0.0380 & -0.1114 & -0.0276 \\
$\mathrm{~A}_{2}$ & 0.3625 & 0.4045 & 0.4212 & -0.2237 & -0.1246 & -0.1961 \\
$\mathrm{~A}_{3}$ & 0.2946 & 0.3386 & 0.3461 & -0.2766 & -0.1899 & -0.2533 \\
$\mathrm{~A}_{4}$ & 0.4847 & 0.3352 & 0.5240 & -0.1824 & -0.2483 & -0.1785 \\
$\mathrm{~A}_{5}$ & 0.6768 & 0.5971 & 0.7647 & -0.0388 & -0.1075 & -0.0277 \\
\hline
\end{tabular}

TABLE 15: Scores of alternatives when $Y_{2}=0$.

\begin{tabular}{|c|c|c|c|c|c|c|}
\hline \multicolumn{7}{|c|}{$Y_{2}=0$} \\
\hline & \multicolumn{3}{|c|}{$Y_{1}=0.5$} & \multicolumn{3}{|c|}{$Y_{1}=-0.5$} \\
\hline & Factor 1 & Factor 2 & Comprehensive factor & Factor 1 & Factor 2 & Comprehensive factor \\
\hline $\mathrm{A} 1$ & 0.4043 & 0.2863 & 0.4421 & 0.4382 & 0.3473 & 0.4844 \\
\hline $\mathrm{A} 2$ & 0.0483 & 0.0796 & 0.0784 & 0.1838 & 0.2762 & 0.2348 \\
\hline A3 & -0.0167 & 0.0162 & 0.0097 & 0.1175 & 0.2031 & 0.1613 \\
\hline $\mathrm{A} 4$ & 0.1832 & 0.0235 & 0.1929 & 0.2584 & 0.1538 & 0.2817 \\
\hline A5 & 0.4095 & 0.3072 & 0.4521 & 0.4379 & 0.3581 & 0.4867 \\
\hline
\end{tabular}

TABLE 16: Scores of alternatives when $Y_{1}=0.5$.

\begin{tabular}{|c|c|c|c|c|c|c|}
\hline \multicolumn{7}{|c|}{$Y_{1}=0.5$} \\
\hline & \multicolumn{3}{|c|}{$Y_{2}=0.5$} & \multicolumn{3}{|c|}{$Y_{2}=-0.5$} \\
\hline & Factor 1 & Factor 2 & Comprehensive factor & Factor 1 & Factor 2 & Comprehensive factor \\
\hline$\overline{A_{1}}$ & 0.6649 & 0.5589 & 0.7429 & -0.0694 & -0.1631 & -0.0635 \\
\hline $\mathrm{A}_{2}$ & 0.3122 & 0.3295 & 0.3608 & -0.3230 & -0.2710 & -0.3063 \\
\hline $\mathrm{A}_{3}$ & 0.2453 & 0.2661 & 0.2865 & -0.3719 & -0.3248 & -0.3576 \\
\hline $\mathrm{A}_{4}$ & 0.4597 & 0.2866 & 0.4924 & -0.2423 & -0.3430 & -0.2453 \\
\hline $\mathrm{A}_{5}$ & 0.6691 & 0.5818 & 0.7543 & -0.0658 & -0.1516 & -0.0582 \\
\hline
\end{tabular}

TABLE 17: Scores of alternatives when $Y_{1}=-0.5$.

\begin{tabular}{|c|c|c|c|c|c|c|}
\hline \multicolumn{7}{|c|}{$Y_{1}=-0.5$} \\
\hline & \multicolumn{3}{|c|}{$Y_{2}=0.5$} & \multicolumn{3}{|c|}{$Y_{2}=-0.5$} \\
\hline & Factor 1 & Factor 2 & Comprehensive factor & Factor 1 & Factor 2 & Comprehensive factor \\
\hline $\mathrm{A}_{1}$ & 0.6853 & 0.5960 & 0.7689 & -0.0075 & -0.0620 & 0.0073 \\
\hline $\mathrm{A}_{2}$ & 0.4090 & 0.4709 & 0.4744 & -0.1322 & 0.0043 & -0.0942 \\
\hline $\mathrm{A}_{3}$ & 0.3420 & 0.4036 & 0.4018 & -0.1883 & -0.0695 & -0.1564 \\
\hline $\mathrm{A}_{4}$ & 0.5085 & 0.3802 & 0.5541 & -0.1256 & -0.1607 & -0.1150 \\
\hline $\mathrm{A}_{5}$ & 0.6844 & 0.6118 & 0.7747 & -0.0125 & -0.0652 & 0.0020 \\
\hline
\end{tabular}

\section{Conclusion}

In the past 10 years, urban rail transit construction in China has already reached a climax. Therefore, the demand for materials and devices required for construction and operation is also increasing. Unforeseen factors existing in construction and operation, such as the uncontrollable weather and incomplete decision information, increase the purchasing management risk of urban rail transit projects, which adds further to the complexity of supplier selection.
The purchase of scientific materials or devices and the selection of suppliers have become some of the main problems for urban rail transit. Currently, Tianjin urban rail transit mainly uses the open tender and comparative method to select suppliers. These methods are easily understood and actionable. However, such methods do not address the problems of personal preference, overlapping information, weights of indicators, and uncertain environment. In contrast with the suppliers for traditional industries, the suppliers of products for the urban rail transit industry must 
meet higher requirements in terms of quality, technology, and timely supply.

In view of the poor operating environment during the construction phase of the subway project and the perennial operation during the operation phase, we summarize the characteristics of subway equipment and establish a supplier evaluation indicator system suitable for subway equipment, which can make up for the lack of research on the existing subway supplier evaluation indicators. We also propose an intuitionistic fuzzy factor analysis model in a random environment. This model inherits the advantages of the original model and can deal with the overlapping effects between incomplete evaluation information and indicators. It also has the following advantages: (1) considering the weight of the original indicators and the opinions of experts, it improves the rationality of the selection results; (2) consider the impact of environmental factors on supplier and product performance. Convert fixed evaluation information into dynamic evaluation information to improve the timeliness of selection results. This model can help the company choose the best supplier in different decision-making environments, which is conducive to the company's rapid adaptation to the dynamically changing external environment, and further enhance the company's competitiveness.

\section{Data Availability}

The numerical application data used to support the findings of this study are available from the corresponding author upon request.

\section{Conflicts of Interest}

The authors declare that they have no conflicts of interest.

\section{Acknowledgments}

This work was supported by the Science and Technology Development Fund of Tianjin Education Commission for Higher Education (2020KJ006).

\section{References}

[1] P. Gabriella, R. R. Yager, and K. T. Atanassov, "Intuitionistic fuzzy graph interpretations of multi-person multi-criteria decision making: generalized net approach," in Proceedings of the Intelligent Systems, International IEEE Conference, IEEE, Varna, Bulgaria, June 2004.

[2] Z. Liao and J. Rittscher, "A multi-objective supplier selection model under stochastic demand conditions," International Journal of Production Economics, vol. 105, no. 1, pp. 150-159, 2007.

[3] W. Ho, X. Xu, and P. K. Dey, "Multi-criteria decision making approaches for supplier evaluation and selection: a literature review," European Journal of Operational Research, vol. 202, no. 1, pp. 16-24, 2010.

[4] K. Govindan, M. Kadziński, and R. Sivakumar, "Application of a novel PROMETHEE-based method for construction of a group compromise ranking to prioritization of green suppliers in food supply chain," Omega, vol. 71, no. 9, pp. 129-145, 2017.
[5] N. Banaeian, H. Mobli, B. Fahimnia, I. E. Nielsen, and M. Omid, "Green supplier selection using fuzzy group decision making methods: a case study from the agri-food industry," Computers \& Operations Research, vol. 89, pp. 337-347, 2018.

[6] J. Girubha, S. Vinodh, and V. KEK, "Application of interpretative structural modelling integrated multi criteria decision making methods for sustainable supplier selection," Journal of Modelling in Management, vol. 11, no. 2, pp. 358-388, 2016.

[7] S. J. Ghoushchi, M. D. Milan, and M. J. Rezaee, "Evaluation and selection of sustainable suppliers in supply chain using new GP-DEA model with imprecise data," Journal of Industrial Engineering International, vol. 14, no. 3, 2018.

[8] Y. N. Wu, Y. M. Ke, C. B. Xu, and L. W. Y. Li, "An integrated decision-making model for sustainable photovoltaic module supplier selection based on combined weight and cumulative prospect theory," Energy, vol. 181, 2019.

[9] L. A. Zadeh, "Fuzzy sets," Information and Control, vol. 8, no. 3, pp. 338-353, 1968.

[10] K. T. Atanassov, "Intuitionistic fuzzy sets," Fuzzy Sets and Systems, vol. 20, no. 1, pp. 87-96, 1986.

[11] R. R. Yager, "On the theory of bags," International Journal of General Systems, vol. 13, no. 1, pp. 23-37, 1986.

[12] Z. Xu and R. R. Yager, "Dynamic intuitionistic fuzzy multiattribute decision making," International Journal of Approximate Reasoning, vol. 48, no. 1, pp. 246-262, 2008.

[13] Z. S. Xu and R. R. Yager, "Intuitionistic fuzzy Bonferroni means," IEEE Transaction on Systems Man and Cybernetics Part BCybemetics, vol. 41, no. 2, pp. 568-578, 2011.

[14] M. Xia, Z. Xu, and B. Zhu, "Geometric Bonferroni means with their application in multi-criteria decision making," Knowledge-Based Systems, vol. 40, no. 3, pp. 88-100, 2013.

[15] J. Qin and X. Liu, "An approach to intuitionistic fuzzy multiple attribute decision making based on Maclaurin symmetric mean operators," Journal of Intelligent \& Fuzzy Systems, vol. 27, no. 5, pp. 2177-2190, 2014.

[16] P. Liu, "Some hamacher aggregation operators based on the interval-valued intuitionistic fuzzy numbers and their application to group decision making," IEEE Transactions on Fuzzy Systems, vol. 22, no. 1, pp. 83-97, 2014.

[17] R. Verma and B. D. Sharma, "Hesitant fuzzy geometric heronian mean operators and their application to multicriteria decision making," Scientiae Mathematicae Japonicae, vol. 78, no. 4, pp. 23-39, 2019.

[18] R. Krishankumar, Y. Gowtham, A. Ifjaz et al., "Solving green supplier selection problem using q-rung orthopair fuzzybased decision framework with unknown weight information," Applied Soft Computing Journal, vol. 94, 2020.

[19] E. K. Zavadskas, Z. Turskis, Stević Ž et al., "Modelling procedure for the selection of steel pipes supplier by applying fuzzy AHP method," Operational Research in Engineering Sciences: Theory and Applications, vol. 3, no. 2, pp. 39-53, 2020.

[20] J. Wang, G.-w. Wei, C. Wei et al., "Maximizing deviation method for multiple attribute decision making under q-rung orthopair fuzzy environment," Defence Technology, vol. 16, no. 5, pp. 1073-1087, 2020.

[21] H.-W. Liu and G.-J. Wang, "Multi-criteria decision-making methods based on intuitionistic fuzzy sets," European Journal of Operational Research, vol. 179, no. 1, pp. 220-233, 2007.

[22] W. J. Wang and Y. Yan, "A SPA method for multiple attribute decision making with score functions[J]," Mathematics in Practice and Theory, vol. 44, no. 13, pp. 72-76, 2014. 
[23] Y. J. Tian, "Multi-criteria decision-making method based on mentality function under interval-valued intuitionistic fuzzy number and its research," Fuzzy Systems and Mathematics, vol. 32, no. 5, pp. 161-165, 2018.

[24] S. Zeng, S.-M. Chen, and L.-W. Kuo, "Multiattribute decision making based on novel score function of intuitionistic fuzzy values and modified VIKOR method," Information Sciences, vol. 488, pp. 76-92, 2019.

[25] F. E. Boran, S. Genç, M. Kurt, and D. Akay, "A multi-criteria intuitionistic fuzzy group decision making for supplier selection with TOPSIS method," Expert Systems with Applications, vol. 36, no. 8, pp. 11363-11368, 2009.

[26] X. Y. Li, "Integrating fuzzy DANP and modified grey relation theory for evaluating green supplier," Commercial Research, vol. 12, pp. 151-157, 2015.

[27] X. Chen, H. Li, C. Tan et al., “An intuitionistic fuzzy factorial analysis model for multi attribute decision-making under random environment," Journal of the Operational Research Society, vol. 70, pp. 1-20, 2018.

[28] N. Jain and A. R. Singh, "Sustainable supplier selection under must-be criteria through Fuzzy inference system," Journal of Cleaner Production, vol. 248, no. 3, pp. 119275.1-119275.20, 2020.

[29] Z. H. Chen, X. G. Ming, T. T. Zhou, and Y. Chang, "Sustainable supplier selection for smart supply chain considering internal and external uncertainty: an integrated rough-fuzzy approach," Applied Soft Computing Journal, vol. 87, 2020.

[30] I. Ali, E. Stevi, C. Karamasa et al., "A novel integrated fuzzy PIPRECIA-interval rough SAW model: green supplier selection," Decision Making: Applications in Management and Engineering, vol. 3, no. 1, pp. 126-145, 2020.

[31] L. Xiao, S. Zhang, G. Wei et al., "Green supplier selection in steel industry with intuitionistic fuzzy Taxonomy method," Journal of Intelligent \& Fuzzy Systems, vol. 39, no. 5, pp. 7247-7258, 2020.

[32] J. Wang, G. Wei, C. Wei et al., "MABAC method for multiple attribute group decision making under q-rung orthopair fuzzy environment," Defence Technology, vol. 16, no. 1, pp. 208-216, 2020.

[33] D. Wei and D. Karabašević, "An extension of the WASPAS method for decision-making problems with intuitionistic fuzzy numbers: a case of website evaluation," Operational Research in Engineering Sciences: Theory and Applications, vol. 1, no. 1, pp. 29-39, 2018.

[34] A. R. Mishra, A. Mardani, P. Rani, and E. K. Zavadskas, "A novel EDAS approach on intuitionistic fuzzy set for assessment of health-care waste disposal technology using new parametric divergence measures," Journal of Cleaner Production, vol. 272, no. 272, Article ID 122807, 2020.

[35] C. Gencer and D. Gürpinar, "Analytic network process in supplier selection: a case study in an electronic firm," Applied Mathematical Modelling, vol. 31, no. 11, pp. 2475-2486, 2007.

[36] S. Mishra, C. Samantra, S. Datta, and S. S. Mahapatra, "Multiattribute group decision-making (MAGDM) for supplier selection using fuzzy linguistic modelling integrated with VIKOR method," International Journal of Services and Operations Management, vol. 12, no. 1, pp. 67-89, 2012.

[37] G. Polat and E. Eray, "An integrated approach using AHP-ER to supplier selection in railway projects," Procedia Engineering, vol. 123, 2015.

[38] P. Murali, V. D. Reddy, and A. D. Phaneendra, "Supplier selection by using multi- criteria decision making methods," International Journal of Engineering Research and General Science, vol. 2, no. 6, 2014.
[39] D. M. Liu and J. Chen, "Research on supplier selection in the strategic purchase mode based on supply chain," Journal of Xi'an Aeronautical University, vol. 31, no. 6, pp. 41-47, 2013.

[40] R. X. Luo and S. N. You, "Manufacturing industry supplier appraises and choice based on rough sets-AHP," Mathematics in Practice and Theory, vol. 43, no. 12, pp. 1-9, 2013. 